\title{
Regimen Used to Treat Myelodysplastic Syndromes
}

National Cancer Institute

\section{Source}

National Cancer Institute. Regimen Used to Treat Myelodysplastic Syndromes. NCI

Thesaurus. Code C159445.

Any regimen that can be used for the treatment of myelodysplastic syndromes (MDS). 